Check for updates

Cite this: RSC Adv., 2017, 7, 24298

Received 16th February 2017 Accepted 23rd April 2017

DOI: $10.1039 / c 7 r a 01964 e$

rsc.li/rsc-advances

\section{Interaction of galacto-oligosaccharides and lactulose with dipalmitoylphosphatidilcholine lipid membranes as determined by infrared spectroscopy}

\author{
Sonia B. Díaz, ${ }^{a}$ Norma M. Ale, ${ }^{a}$ Aida Ben Altabef, ${ }^{\text {ab }}$ Elizabeth Tymczyszyn (DD *c \\ and Andrea Gomez-Zavaglia (iD)
}

Lactulose and galacto-oligosaccharides (GOS) have been recognized as health promoting compounds due to their recognized prebiotic capacity. In addition, because of their polyhydroxilated nature, they are effective protectants during processes involving dehydration of lactic acid bacteria. The protective effects of sugars have been associated with their capacity to replace water molecules from lipid membranes and/or to form glassy matrices. Although this latter property has been previously investigated for GOS and lactulose, the capacity of these sugars to replace water molecules was not. Furthermore, it must be considered that GOS are usually mixtures of oligo-saccharides with different degrees of polymerization (DP) including or excluding different amounts of mono and disaccharides, and the effect of their composition on the GOS-membrane interaction has not been addressed so far. The aim of the present work was to study the interaction of lactulose and GOS of different compositions with dipalmitoylphosphatidilcholine (DPPC) membranes both in the gel $\left(\mathrm{L}_{\beta}\right)$ and in the liquid crystalline phase $\left(L_{\alpha}\right)$ by using infrared spectroscopy. Both GOS and lactulose interacted with the phosphate groups of the polar head region, but only lactulose (disaccharide) penetrated into the lipid bilayers and decreased the membrane phase transition $\left(T_{m}\right)$. In contrast, GOS containing no mono and disaccharides were excluded from the hydrophobic region, leading to an increase of the $T_{\mathrm{m}}$. In turn, GOS containing mono and disaccharides showed a concentration-dependent effect. The results obtained shed light on the mechanisms involved in protection mediated by GOS and lactulose, thus providing support to improve the stabilization of lactic acid bacteria.

\section{Introduction}

Galacto-oligosaccharides (GOS) and lactulose are sugars with recognized prebiotic properties, that is, "non-digestible food ingredients that selectively stimulate the growth and/or activity of one or a limited number of bacterial species already resident in the colon, thus attempting to improve the host health". ${ }^{1}$ From a chemical point of view, GOS are composed of a variable number of galactose units (usually from two to ten) and a terminal glucose unit, mostly linked by $\beta 1-4$ and $\beta 1-6$ bonds. ${ }^{2,3}$

${ }^{a}$ Instituto de Química Física, Facultad de Bioquímica, Química y Farmacia, Universidad Nacional de Tucumán, San Lorenzo 456, T4000CAN Tucumán, Argentina ${ }^{b}$ Instituto de Química del Noroeste Argentino (INQUINOA), CCT CONICET Tucumán, T4000CAN, Argentina

${ }^{c}$ Laboratorio de Microbiología Molecular, Departamento de Ciencia y Tecnología, Universidad Nacional de Quilmes, Bernal, Buenos Aires, Argentina.E-mail: elitym@ yahoo.com.ar

${ }^{d}$ Center for Research and Development in Food Cryotechnology, CCT-CONICET La Plata, RA-1900, Argentina
In turn, lactulose is a disaccharide (4-O- $\beta$-D-galactopyranosyl-Dfructose) produced by isomerization of lactose ${ }^{4-8}$ (Scheme 1).

The carbohydrate nature of GOS and lactulose supports their capacity to protect lactic acid bacteria during freeze-drying ${ }^{\mathbf{9 - 1 4}}$
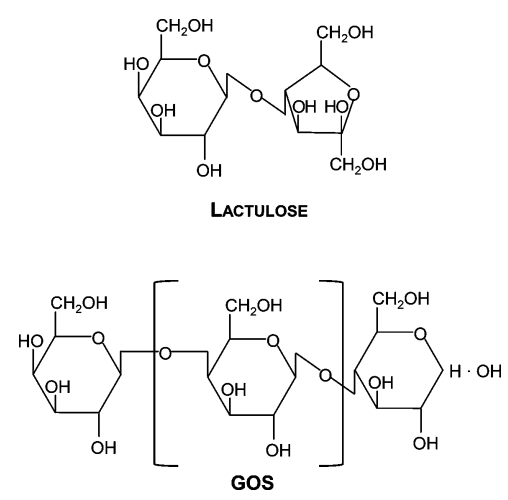

Scheme 1 Schematic representation of the lactulose and GOS molecules. For GOS, $n$ represents the number of galactose units and it can be within 1 and 6 . 
and spray-drying. ${ }^{12,15}$ These protective properties can be explained on the basis of their ability to form glassy matrices of high viscosity and low molecular mobility, where molecular interactions are restricted (vitrification hypothesis of lyoprotection). ${ }^{10,13}$ The thermophysical properties of these glassy matrices are of great importance for long term storage of dehydrated microorganisms. ${ }^{\mathbf{9}, 10,13}$ However, the glassy state is a necessary but not sufficient condition to explain the protective capacity of sugars. Sugars can replace water molecules during drying, thus preserving the structures and physiological functions of cellular macromolecules, and precluding bacterial damage and/or death in the dried state. ${ }^{16}$ As lipid membranes are the main target of damage during dehydration, their interaction with sugars play a vital role in maintaining their structural integrity and appropriate functioning. ${ }^{17,18}$ In the anhydrous state, lipids are closely packed because of the loss of hydration water from their polar head. This increases van der Waals interactions among the hydrocarbon chains and hence, the phase transition temperature from the gel to the liquidcrystalline state $\left(T_{\mathrm{m}}\right)$ also increases. ${ }^{19}$ This leads to highly ordered lipids more closely packed, thus being more prone to rupture and leakage after rehydration treatment of membrane. ${ }^{20}$

Different authors have reported that dehydrating liposomes in the presence of disaccharides prevents leakage and fusion during drying and storage. ${ }^{16,21,22}$ Sugars like trehalose or sucrose, directly interact with the polar heads of lipids by establishing hydrogen bonds, and replacing water molecules. These compounds have different effects on the water bound to carbonyls and phosphates. Trehalose replaces water molecules both in carbonyls and phosphates. In contrast, sucrose only replaces water molecules from phosphates, and dehydrates carbonyls. ${ }^{23,24}$

Fourier transform infrared (FTIR) spectroscopy is a powerful, non-destructive and versatile technique, very useful for the detection and characterization of lipid phase transitions in model membranes, and to obtain structural and organizational information. Because of its sensitivity to hydrogen bonds, FTIR has been widely used to determine the interaction of sugars with lipid membranes, thus contributing to understand the molecular mechanisms involved in the protection mediated by sugars..$^{25-28}$ In this sense, FTIR has been used to determine the effect of different sugars (i.e.: sucrose, trehalose, fructans) on carbonyl and phosphate groups, as well as on the lipid package (and thus, on their $T_{\mathrm{m}}$ ). ${ }^{29-32}$

Hincha et al. ${ }^{27}$ used FTIR to investigate the interaction of fructans and gluco-oligosaccharides with phosphates in model systems. They also determined the capacity of these sugars to decrease the $T_{\mathrm{m}}$, thus explaining the protective effect of the studied oligo-saccharides on the membrane stability during air-drying. Using multiparametric flow cytometry, we have recently determined that GOS and lactulose are able to preserve membrane integrity during desiccation of Lactobacillus delbrueckii subsp. bulgaricus. ${ }^{11}$ However, the molecular mechanisms involved in the interaction of GOS or lactulose with lipid membranes have not been addressed hereto. To shed light on these mechanisms, the aim of the present work was to study the molecular interaction of two GOS of different composition (GOS Cup-Oligo H-70® and GOS Biotempo) and lactulose with 1,2-dipalmitoyl-sn-glycero-3-phosphocholine (DPPC) model systems, both in the gel $\left(\mathrm{L}_{\beta}\right)$ and in the liquid crystalline phase $\left(\mathrm{L}_{\alpha}\right)$, by FTIR, as a valid approach to assess the molecular mechanisms involved in the protection mediated by GOS and lactulose.

\section{Results and discussion}

Investigating the shifts of the symmetric and asymmetric $\mathrm{PO}_{2}{ }^{-}$ stretching $\left(\nu_{\mathrm{s}} \mathrm{PO}_{2}{ }^{-}\right.$and $\left.\nu_{\text {as }} \mathrm{PO}_{2}{ }^{-}\right)$and $\mathrm{C}=\mathrm{O}$ stretching $(\nu \mathrm{C}=\mathrm{O})$ vibrational modes (free and bound, $\nu \mathrm{C}=\mathrm{O}_{\mathrm{f}}$ and $\nu \mathrm{C}=\mathrm{O}_{\mathrm{b}}$ ) provided information about the interaction of GOS and lactulose with the hydrophilic region of DPPC membranes in the gel $\left(25^{\circ} \mathrm{C}\right)$, in the liquid crystalline state $\left(50^{\circ} \mathrm{C}\right)$ and at the transition temperature $\left(42^{\circ} \mathrm{C}\right)($ Fig. $1 \mathrm{~A}-\mathrm{C})$.

The position of the phosphate related bands shifted to lower wavenumbers in the presence of 9 and $18 \% \mathrm{w} / \mathrm{w}$ lactulose and GOS Biotempo at the three temperatures assayed $(25,42$ and 50 ${ }^{\circ} \mathrm{C}$ ). At $38 \% \mathrm{w} / \mathrm{v}$, an opposite behavior was observed (Fig. 1A-C). On the contrary, when the concentration of GOS Biotempo was $38 \% \mathrm{w} / \mathrm{v}$, the $\nu_{\mathrm{S}} \mathrm{PO}_{2}{ }^{-}$was observed at higher wavenumbers (Fig. 1C). At this concentration, no changes in the position of the $\nu_{\mathrm{s}} \mathrm{PO}_{2}{ }^{-}$bands were observed in the presence of lactulose (Fig. 1A). For GOS Cup-Oligo $\mathrm{H}-70 ®, \nu_{\text {as }} \mathrm{PO}_{2}{ }^{-}$shifted to higher wavenumbers whereas $\nu_{\mathrm{s}} \mathrm{PO}_{2}{ }^{-}$, did not shift. This behavior was observed at all the three temperatures assayed (Fig. 1B).

In turn, the position of the bands ascribed to both the free and bound $\mathrm{C}=\mathrm{O}$ groups $\left(\nu \mathrm{C}=\mathrm{O}_{\mathrm{f}}\right.$ and $\left.\nu \mathrm{C}=\mathrm{O}_{\mathrm{b}}\right)$ was not modified by the addition of both GOS (Biotempo and Cup-Oligo H-70®) and lactulose neither in the gel nor in the liquid crystalline phases (Fig. 1A-C).

The slight shift decrease observed at $38 \% \mathrm{w} / \mathrm{w}$ lactulose and GOS, and in certain cases the shifts varying from negative to positive values can be ascribed to a slight weakening of the H-bonding.

We encourage to attribute the reduction of the (lipid) $-\mathrm{PO}_{2} \cdots$ sugar or (lipid) $-\mathrm{C}=\mathrm{O} \cdots$ sugar interactions to the possible exclusion of sugars out of the bilayer caused by very high sugar : lipid ratios. This opposite effect was previously ascribed to the interaction of sugars with biomembranes. ${ }^{37}$ In fact, it was found that the "interaction" or "exclusion" hypotheses depend on the sugar concentration. Moiset et al. (2014) reported the presence of membrane defects when sugars interact with lipids. Thus, oligo-saccharides' interaction may be conditioned by the different hydration levels present at the phosphate groups or by defects in the bilayer formation resulting from osmotic effects. Moreover, the ability of sugars to modify the lateral organization of lipids depends in great extend on their geometry and chemical properties (reducing or not reducing mono or disaccharides). ${ }^{38}$ The mismatch of the water network introduces an energetically unfavorable penalty at the interface where the two networks join. ${ }^{38}$ This behavior indicates that GOS (both CupOligo $\mathrm{H}-70 \circledR$ and Biotempo) and lactulose establish hydrogen bonds with the $\mathrm{PO}_{2}{ }^{-}$groups of the polar head of DPPC (especially in the gel state). 

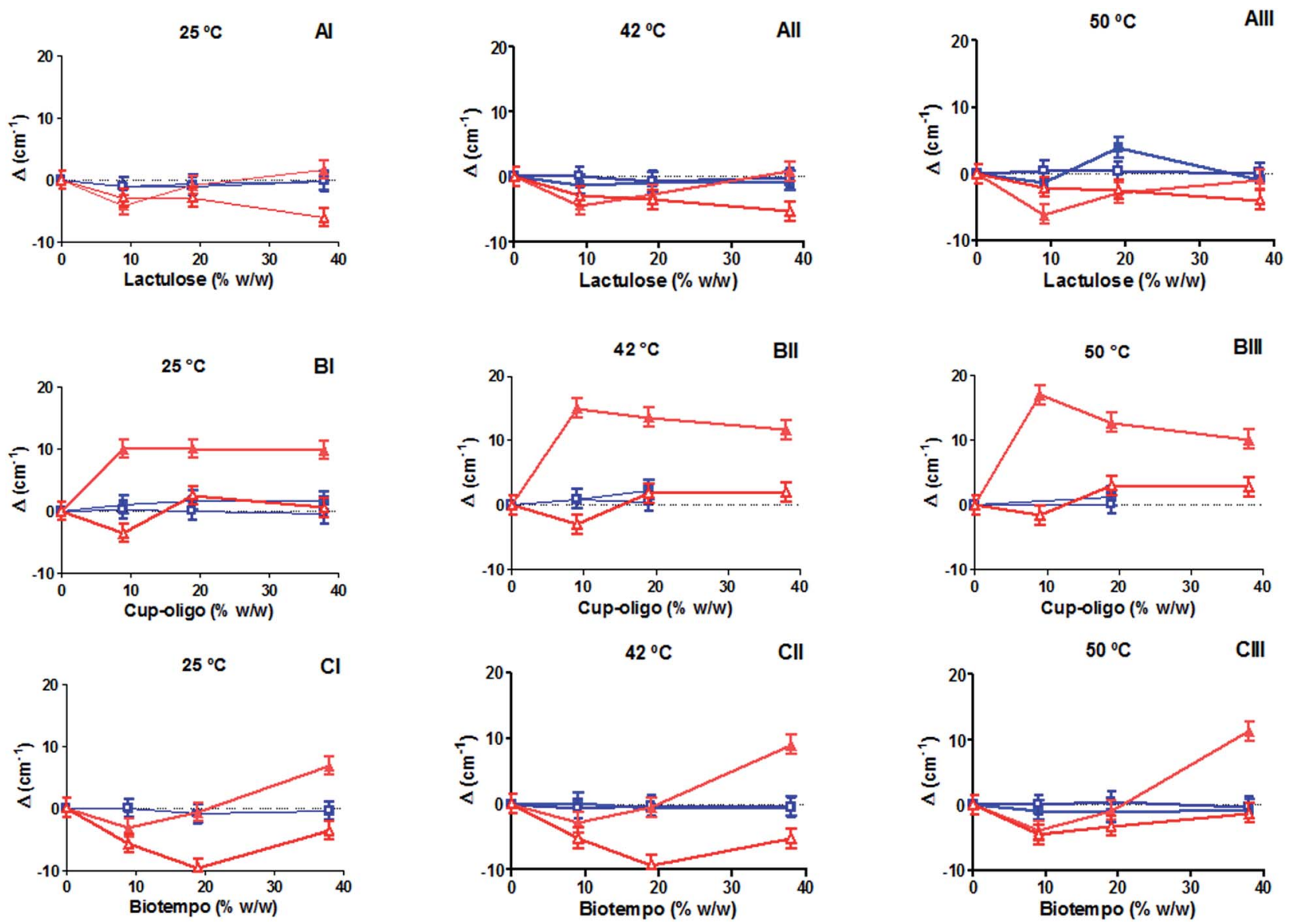

Fig. 1 Wavenumber shifts of $\nu \mathrm{C}=\mathrm{O}_{\mathrm{f}}(\square), \nu \mathrm{C}=\mathrm{O}_{\mathrm{b}}(\square), \nu_{\mathrm{as}} \mathrm{PO}_{2}^{-}(\Delta)$ and $\nu_{\mathrm{s}} \mathrm{PO}_{2}^{-}(\triangle)$, as a function of the prebiotic concentration at different temperatures. Lactulose: (AI) $25^{\circ} \mathrm{C}$ (gel state), (All) $42{ }^{\circ} \mathrm{C}$ (transition temperature) and (Alll) $50{ }^{\circ} \mathrm{C}$ (liquid crystalline state). Cup-oligo: (BI) $25{ }^{\circ} \mathrm{C}$ (gel state), (BII) $42{ }^{\circ} \mathrm{C}$ (transition temperature) and (BIII) $50{ }^{\circ} \mathrm{C}$ (liquid crystalline state). Biotempo: (Cl) $25^{\circ} \mathrm{C}$ (gel state), (CII) $42{ }^{\circ} \mathrm{C}$ (transition temperature) and (CIII) $50{ }^{\circ} \mathrm{C}$ (liquid crystalline state) the value of 0 corresponds to DPPC liposomes prepared without sugars.

Although the interaction of both types of GOS and lactulose did not have any significant effect on the position of $\nu \mathrm{C}=\mathrm{O}$ vibrational modes (Fig. $1 \mathrm{~A}-\mathrm{C}$ ), different effects have been observed when analyzing the contribution of bound and free carbonyl populations (Fig. 2). DPPC liposomes were composed of $72 \%$ of bound carbonyls and this percentage slightly increased above the $T_{\mathrm{m}}$ (from 72 to $80 \%$ ). The incorporation of $9 \% \mathrm{w} / \mathrm{w}$ lactulose did not significantly modify the contribution of bound carbonyls. This contribution was lower than that of DPPC, when added at $20 \% \mathrm{w} / \mathrm{w}$. The addition of $38 \% \mathrm{w} / \mathrm{w}$ lactulose led to a continuous increase of the hydrated population (Fig. 2A). This could be ascribed to the increase of water in the polar head group interface due to the insertion of this disaccharide in the membrane.

In turn, for DPPC:GOS Cup-Oligo H-70® liposomes the contribution of bound carbonyl population $\left(\nu \mathrm{C}=\mathrm{O}_{\mathrm{b}}\right)$ was lower than that of DPPC liposomes in the gel phase, and was not significantly different in the liquid crystalline phase. It was not possible to deconvolve the $\nu \mathrm{C}=\mathrm{O}$ band at $38 \% \mathrm{w} / \mathrm{w}$ GOS CupOligo $\mathrm{H}-70 \circledR$ because the high concentration of GOS led to an overlap of bands, thus making difficult the elucidation of carbonyl and sugar bands (Fig. 2B).

In the case of GOS Biotempo, at $9 \% \mathrm{w} / \mathrm{w}$ the contribution of hydrated carbonyls $\left(\nu \mathrm{C}=\mathrm{O}_{\mathrm{b}}\right)$ was higher than that in DPPC liposomes. At 20 and $38 \% \mathrm{w} / \mathrm{w}$, the behavior was similar to that of DPPC (Fig. 2C). These results seem to indicate that the disaccharide lactulose is the only prebiotic sugar able to insert in the lipid membrane, when used in high concentrations (38\% $\mathrm{w} / \mathrm{v}$ ). In order to corroborate this hypothesis the effect of GOS and lactulose interaction on membrane packing, was evaluated by determining the $T_{\mathrm{m}}$, as the shift of $\nu_{\mathrm{as}} \mathrm{CH}_{2}$ vibrational mode. The $\mathrm{CH}_{2}$ stretching vibrational modes give rise to bands in the $3100-2800 \mathrm{~cm}^{-1}$ spectral region, with the $\mathrm{CH}_{2}$ antisymmetric and symmetric stretching modes located at $\sim 2920$ and $\sim 2850$ $\mathrm{cm}^{-1}$, respectively. The frequencies of these bands are conformation sensitive and respond to temperature induced changes of the trans-gauche ratio of carbon-carbon bonds in the acyl chains. ${ }^{39}$ An increased proportion of gauche conformers in the acyl chains corresponds to a shift of the absorption maxima of both $\mathrm{CH}_{2}$ stretching vibrations to higher wavenumbers. The absorption of this band shifts to higher wavenumbers when 

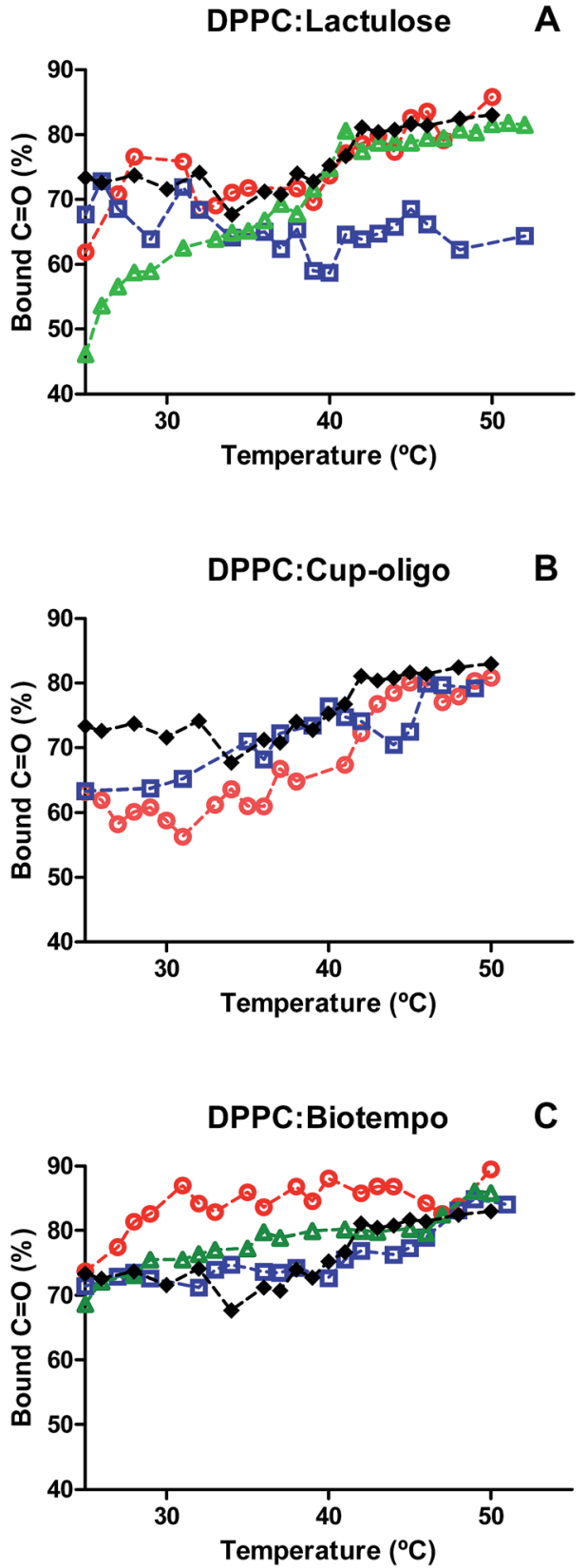

Fig. 2 Contribution of $\nu \mathrm{C}=\mathrm{O}_{\mathrm{b}}$ to the total carbonyl population at different temperatures. (A) DPPC:lactulose, (B) DPPC:GOS Cup-Oligo H-70®, (C) DPPC:GOS Biotempo. DPPC ( ), 9\% w/w (0), 19\% w/w ( $\square)$ and $38 \% \mathrm{w} / \mathrm{w}(\triangle)$ of sugars in DPPC:sugars' systems.

membranes become fluid, that is, when the population of gauche hydrocarbon chain conformation becomes higher than that of the trans conformation. Thus, the phase change that takes place when the hydrocarbon chains of the hydrophobic center melt during the transition gel $\left(\mathrm{L}_{\beta}{ }^{\prime}\right)$-crystalline liquid $\left(\mathrm{L}_{\alpha}\right)$ phase of the phospholipids. The frequency jump temperature corresponds to the phospholipid transition temperature $T_{\mathrm{m}}$. Cooperativity is a measure of the proportion of lipid chains that simultaneously change during phase transitions.

The $T_{\mathrm{m}}$ of DPPC membranes in the presence of different concentrations of GOS and lactulose was determined by plotting the position of the $\nu_{\text {as }} \mathrm{CH}_{2}$ vibrational mode as a function of temperature. The data were fitted with a sigmoidal function equation (eqn (1)) using Graphpad program (version 5.01).

$$
\nu_{(T)}=\left[\nu_{\min }+\left(\nu_{\max }-\nu_{\min }\right)\right] /\left\{1+\left[10^{\left(T_{\mathrm{m}}-T\right) \beta}\right]\right\}
$$

where $\nu_{\min }$ is the wavenumber in the gel state, $\nu_{\max }$ is the wavenumber in the liquid crystalline state, $T$ is the temperature in ${ }^{\circ} \mathrm{C}, T_{\mathrm{m}}$ is the melting temperature $\left({ }^{\circ} \mathrm{C}\right)$ and $\beta$ reflects the hill slope and is equivalent to cooperativity (Fig. 3 and Table 1).

The presence of GOS Biotempo (mainly composed of oligosaccharides with degrees of polymerization (DP) 3 and 4: DP3
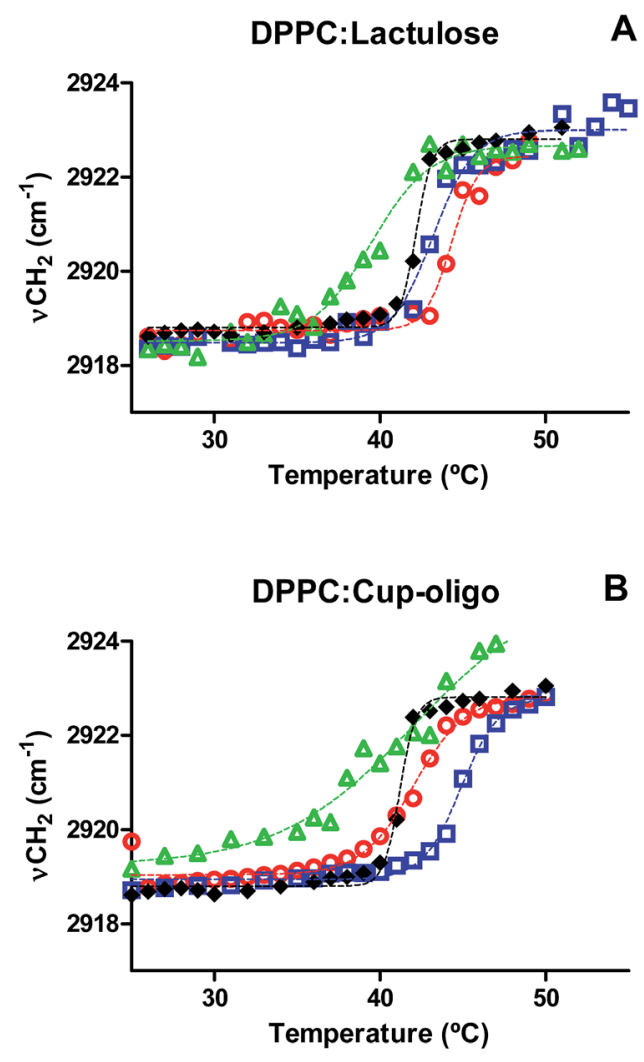

DPPC:Biotempo C

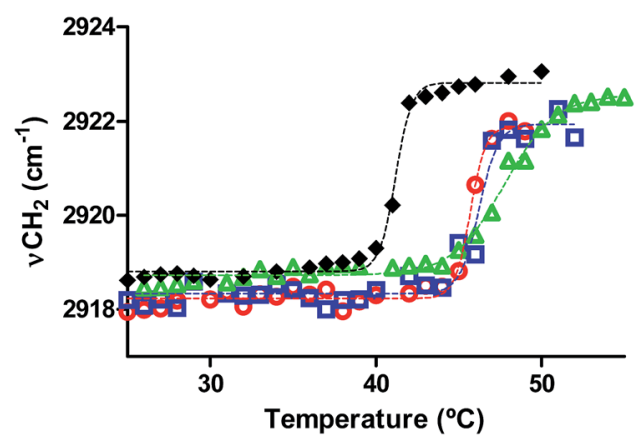

Fig. 3 Position of the $\nu_{\text {as }} \mathrm{CH}_{2}$ vibrational mode as a function of temperature for: (A) DPPC:lactulose, (B) DPPC:GOS Cup-Oligo H$70 \circledast$, (C) DPPC:GOS Biotempo. DPPC ( $\diamond), 9 \% \mathrm{w} / \mathrm{w}(0), 19 \% \mathrm{w} / \mathrm{w}(\square)$ and $38 \% \mathrm{w} / \mathrm{w}(\triangle)$ of sugars in DPPC:sugars' systems. Experimental points were fitted using eqn (1). 
Table $1 T_{m}$ and cooperativity $(\beta)$ of the different DPPC:sugar formulations obtained by fitting the experimental points of Fig. 3 using eqn (1). n.d.: not determined

\begin{tabular}{lclll}
\hline Condition & {$[$ Sugar $\% \% \mathrm{w} / \mathrm{w}$} & $T_{\mathrm{m}}\left({ }^{\circ} \mathrm{C}\right)$ & $\beta$ & $R^{2}$ \\
\hline DPPC & 0 & $41.20 \pm 0.08$ & 0.90 & 0.99 \\
DPPC:lactulose & 9 & $44.33 \pm 0.19$ & 0.55 & 0.97 \\
& 19 & $43.22 \pm 0.22$ & 0.35 & 0.98 \\
DPPC:Cup-oligo H-70® & 38 & $39.48 \pm 0.28$ & 0.25 & 0.98 \\
& 9 & $42.06 \pm 0.21$ & 0.28 & 0.99 \\
& 19 & $44.90 \pm 0.13$ & 0.38 & 0.99 \\
DPPC:Biotempo & 38 & n.d. & n.d. & n.d. \\
& 9 & $45.71 \pm 0.09$ & 0.93 & 0.98 \\
& 19 & $46.25 \pm 0.18$ & 0.75 & 0.96 \\
& 38 & $47.75 \pm 0.18$ & 0.28 & 0.99
\end{tabular}

and DP4, see Section 4.1) led to an increase of $T_{\mathrm{m}}$ at all the concentrations assayed (Fig. 3C and Table 1), with an increase in the cooperativity as a function of the concentration. Lactulose had the same behavior than GOS, only at $9 \% \mathrm{w} / \mathrm{v}$ (Fig. 3A and Table 1). At high concentrations $(38 \% \mathrm{w} / \mathrm{v})$, the $T_{\mathrm{m}}$ value was lower than that of DPPC. This indicates a fluidification of the lipid bilayer in the gel state as a result of the insertion of lactulose disaccharide in the polar head region of the membrane. The insertion of disaccharides in lipid membranes was previously reported for other sugars such as trehalose and sucrose. ${ }^{16,23,36}$ In addition, the insertion of high concentrations of lactulose $(38 \% \mathrm{w} / \mathrm{v})$ in the bilayer could be related with an osmotic effect, thus being representative of the protective effect during drying (Scheme 2A).

In the case of GOS Cup-Oligo $\mathrm{H}-70 \AA$, two different effects were observed. At 9 and $19 \% \mathrm{w} / \mathrm{w}$, the $T_{\mathrm{m}}$ increased and cooperativity decreased with regard to DPPC liposomes prepared without the addition of any sugar, and at $38 \% \mathrm{w} / \mathrm{v}$ a dramatically fluidification of the gel phase were observed (Fig. 3B). This effect could be the result of a different behavior arising from oligo-saccharides with different degrees of polymerization. Whereas high concentrations of GOS induce osmotic effects, mono and disaccharides might insert into the lipid bilayer, fluidifying the hydrophobic region (Scheme 2B). The presence of high concentrations of Cup-Oligo $\mathrm{H}-70 \circledast$ and lactulose $(38 \%$ $\mathrm{w} / \mathrm{w}$ ) caused shifts in the $\nu \mathrm{CH}_{2}$ vibrational modes, indicating an increase of the contribution of gauche conformers below $T_{\mathrm{m}}$ (less order) and an increase of this contribution above $T_{\mathrm{m}}$. As Cup-Oligo $\mathrm{H}-70 \circledast$ intercalates into the phospholipid bilayer, it could withdraw phospholipid molecules from cooperative lipid phase, indicating that domains are less compact and thus, with low cooperativity for transition $(\beta=0.11)$ (Table 1$)$. A similar effect on the cooperativity is observed for lactulose. However, for GOS Biotempo, a significantly decrease of cooperativity was observed only at $38 \% \mathrm{w} / \mathrm{v}$. This is in consistent with the results shown in Fig. 3C and 1, in which GOS containing oligosaccharides of higher DP (GOS Biotempo) interacted with phosphate groups, but remained excluded because of their incapacity to penetrate into the polar head of lipid bilayers. This exclusion leads to a loss of water from this region and to an increase of the $T_{\mathrm{m}}$ (Scheme 2C).
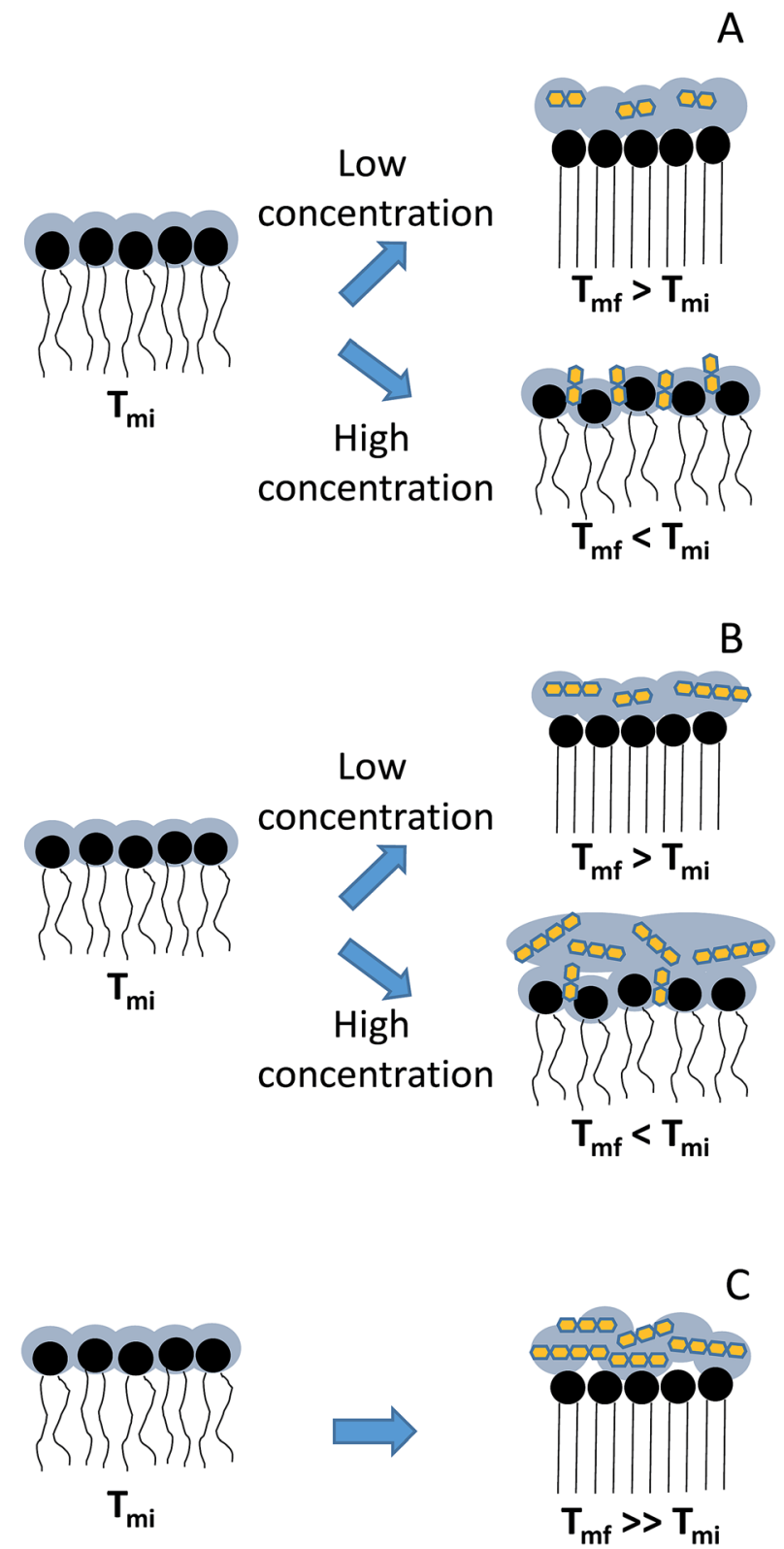

Scheme 2 Schematic representation of the interaction of GOS and lactulose with DPPC: (A) lactulose, (B) GOS Cup-oligo and (C) GOS Biotempo. $T_{\mathrm{mi}}$ corresponds to the initial membrane transition phase temperature and $T_{\mathrm{mf}}$, to final membrane transition phase temperature points were fitted using eqn (1).

\section{Conclusions}

In this work, the interaction of three prebiotic oligo-saccharides (two GOS of different composition and lactulose) with lipid membranes has been assessed. All of them showed to interact with the phosphate polar head groups. However, the DP of GOS and the concentration of sugars had a differential effect on the physico-chemical properties of carbonyls and of the hydrophobic region.

Taking into account these results, we can conclude that the impact of both hypotheses of membrane protection in the dried 
state (water replacement or vitrification) depend on the molecular weight of the oligosaccharide under consideration. For oligosaccharides of low DP the water replacement appears as the predominant mechanism, whereas for those of higher $\mathrm{DP}$, the vitrification effect (by exclusion of water from the interface) is the prevalent hypothesis.

\section{Experimental}

\subsection{Galacto-oligosaccharides and lactulose}

Two types of GOS were studied: a commercial syrup consisting in mixtures of galacto-oligosaccharides containing galactose and glucose as monomers (Cup Oligo H-70®, Kowa Company, Tokyo, Japan) kindly donated by Kochi S.A. (Santiago, Chile), and GOS Biotempo, consisting in mixtures of galactooligosaccharides obtained by enzymatic synthesis and further removal of mono and disaccharides, at Biotempo S.L. (Guimarães, Portugal) that were kindly donated for this study. Cup Oligo H-70® contained $75 \%$ GOS of different degrees of polymerization: $4 \%$ of high-molecular-weight oligo-saccharides (DP $\geq 5$ ), $21 \%$ of tetrasaccharides (DP4), $47 \%$ of trisaccharides (DP3), $23 \%$ of disaccharides (DP2) and lactose, and $5 \%$ of monosaccharides, including glucose and galactose. ${ }^{14}$ GOS Biotempo contained $97 \%$ GOS of different DP: $8 \%$ of pentasaccharides (DP5), $42 \%$ of tetrasaccharides (DP4) and $47 \%$ of trisaccharides (DP3)..$^{33}$

Commercial lactulose [(4-O- $\beta$-D-galactopyranosyl- $(1 \rightarrow 4)-\beta$-Dfructofuranose)] was provided by Discovery fine chemicals (Wimborne, UK) (purity 95\%).

\subsection{Liposomes' preparation}

Synthetic DPPC was purchased from Sigma-Aldrich (Buenos Aires, Argentina). Lipids were dissolved in chloroform, dried under a nitrogen stream to form a film, and left for $24 \mathrm{~h}$ under vacuum to ensure the proper removal of solvents. The lipid films were rehydrated in solutions containing 10,20 and $38 \% \mathrm{w} /$ $\mathrm{w}$ GOS or lactulose. Multilamellar vesicles (MLV's) were prepared by gently shaking at $50{ }^{\circ} \mathrm{C}$ (above the $T_{\mathrm{m}}$ ) for 15 minutes. The final concentration of MLV's was $50 \mathrm{mg} \mathrm{mL}{ }^{-1}{ }^{34}$

\subsection{FTIR spectra}

FTIR spectra were recorded in transmission mode in a system continuously purged with dry air, on a Perkin Elmer GX spectrophotometer provided with a deuterated-triglycine sulfate (DTGS) detector. The equipment was coupled to SPV1.0 system that transfer energy by means of a semiconductor cell working with the Peltier effect. The infrared spectra of liposomes were registered on ZnSe windows, every $2{ }^{\circ} \mathrm{C}$ within the 25-50 \pm $0.5^{\circ} \mathrm{C}$ range. Each spectrum was recorded by co-adding 64 scans with $1 \mathrm{~cm}^{-1}$ resolution.

Spectral analysis was carried out using Omnic v.8.3 mathematical software provided by the manufacturer. The contours of the $\mathrm{C}=\mathrm{O}$ stretching bands $(\nu \mathrm{C}=\mathrm{O})$ were obtained by Fourier self deconvolution using bandwidth parameters between 18 and $20 \mathrm{~cm}^{-1}$ and a band narrowing factor of 1.6-2.2, followed by curve fitting to obtain the band's intensities.
Deconvolution was used to determine the position of the bands corresponding to the two populations of carbonyl groups reported: the non-hydrated (centered at $1742 \mathrm{~cm}^{-1}$ ) and the hydrated (centered at $1724 \mathrm{~cm}^{-1}$ ) populations in the gel state, and the non-hydrated $\left(1737 \mathrm{~cm}^{-1}\right)$ and hydrated $\left(1722 \mathrm{~cm}^{-1}\right)$ populations in the fluid state..$^{35,36}$ The shifts of these two populations were studied as a function of the sugar concentration both in the gel and in the liquid crystalline states.

\subsection{Reproducibility of the results}

Mean values of the main bands in each condition (gel and liquid crystalline states) were obtained from a total of three independent liposome preparations. The standard deviation of the wavenumber shift calculated from this pool of data was about $\pm 1.5 \mathrm{~cm}^{-1}$ in all the conditions assayed.

\section{Acknowledgements}

This work was supported by the Argentinean Agency for the Scientific and Technological Promotion (ANPCyT) (Projects PICT2013-0697, PICT/2014/0912 and PICT/2014/1395), the Argentinean National Research Council (CONICET) (PIP 0205 and 0100636) and CIUNT (PIUNT D542/3) Universidad Nacional de Tucumán, Tucumán, Argentina. A. B. A., E. E. T and A. G.-Z are members of the research career CONICET.

\section{References}

1 G. R. Gibson and M. B. Roberfroid, J. Nutr., 1995, 125, 401.

2 T. Casci and R. A. Rastall, in Prebiotics: Development and Applications, ed. G. R. Gibson and R. A. Rastall, John Wiley, 2006.

3 C. Vera, C. Guerrero, A. Illanes and R. Conejeros, Biotechnol. Bioeng., 2011, 108, 2270.

4 E. Marconi, M. C. Messia, A. Amine, D. Moscone, F. Vernazza, F. Stocchi and G. Palleschi, Food Chem., 2003, 84, 447.

5 F. Zokaee, T. Kaghazchi, A. Zare and M. Soleimani, Process Biochem., 2002, 37, 629.

6 M. Aider and D. de Halleux, Trends Food Sci. Technol., 2007, 18, 356 .

7 C. Guerrero, C. Vera, F. Plou and A. Illanes, J. Mol. Catal. B: Enzym., 2011, 72, 206.

8 Y. S. Kim and D. K. Oh, Bioresour. Technol., 2012, 104, 668.

9 M. Santos, E. Gerbino, C. Araujo-Andrade, E. Tymczyszyn and A. Gómez-Zavaglia, Food Res. Int., 2014, 59, 53.

10 M. I. Santos, C. Araujo-Andrade, E. E. Tymczyszyn and A. Gómez-Zavaglia, Food Res. Int., 2014, 64, 514.

11 M. I. Santos, C. Araujo-Andrade, E. Esparza-Ibarra, E. Tymczyszyn and A. Gómez-Zavaglia, Biotechnol. Prog., 2014, 30, 1231.

12 M. Golowczyc, C. Vera, M. Santos, C. Guerrero, P. Carasi, A. Illanes, A. Gómez-Zavaglia and E. E. Tymczyszyn, J. Dairy Res., 2013, 80, 374. 
13 E. E. Tymczyszyn, N. Sosa, E. Gerbino, A. Hugo, A. GómezZavaglia and C. Schebor, Int. J. Food Microbiol., 2012, 155, 217.

14 E. E. Tymczyszyn, E. Gerbino, A. Illanes and A. GómezZavaglia, Cryobiology, 2011, 62, 123.

15 N. Sosa, E. Gerbino, M. A. Golowczyc, C. Schebor, A. GómezZavaglia and E. E. Tymczyszyn, Front. Microbiol., 2016, 7, 584-592.

16 J. H. Crowe, J. F. Carpenter and L. M. Crowe, Annu. Rev. Physiol., 1998, 60, 73.

17 J. Milhaud, Biochim. Biophys. Acta, Biomembr., 2004, 1663, 19. 18 J. G. Beck, D. Mathieu, C. Loudet, S. Buchoux and E. J. Dufourc, FASEB J., 2007, 21, 1714.

19 J. V. Ricker, N. M. Tsvetkova, W. F. Wolkers, C. Leidy, F. Tablin, M. Longo and J. H. Crowe, Biophys. J., 2003, 84, 3045.

20 J. H. Crowe, L. M. Crowe and F. A. Hoekstra, J. Bioenerg. Biomembr., 1989, 21, 77.

21 H. Oldenhof, W. F. Wolkers, F. Fonseca, S. Passot and M. Marin, Biotechnol. Prog., 2005, 21, 885.

22 N. M. Tsvetkova, B. L. Phillips, L. M. Crowe, J. H. Crowe and S. H. Risbud, Biophys. J., 1998, 75, 2947.

23 M. D. C. Luzardo, F. Amalfa, A. M. Nuñez, S. Diaz, A. B. De Lopez and E. A. Disalvo, Biophys. J., 2000, 78, 2452.

24 S. B. Diaz, D. L. A. Biondi and E. A. Disalvo, Chem. Phys. Lipids, 2003, 122, 153.

25 S. B. Leslie, E. Israeli, B. Lighthart, J. H. Crowe and L. M. Crowe, Appl. Environ. Microbiol., 1995, 61, 3592.
26 M. I. Santos, E. Gerbino, E. Tymczyszyn and A. GomezZavaglia, Foods, 2015, 4, 283.

27 D. K. Hincha, E. Zuther, E. M. Hellwege and A. G. Heyer, Glycobiology, 2002, 12, 103.

28 D. K. Hincha, E. Zuther and A. G. Heyer, Biochim. Biophys. Acta, Biomembr., 2003, 1612, 172.

29 R. N. Lewis and R. N. McElhaney, Methods Mol. Biol., 2007, 400, 207.

30 J. H. Crowe, F. A. Hoekstra, L. M. Crowe, T. J. Anchordoguy and E. Drobnis, Cryobiology, 1989, 26, 76.

31 H. H. Mantsch and R. N. McElhaney, Chem. Phys. Lipids, 1991, 57, 213.

32 S. B. Leslie, S. A. Teter, L. M. Crowe and J. H. Crowe, Biochim. Biophys. Acta, Biomembr., 1994, 1192, 7.

33 D. P. M. Torres, M. Bastos, M. P. F. Goncalves, J. A. Teixeira and L. R. Rodrigues, Carbohydr. Polym., 2011, 83, 831.

34 A. D. Bangham, M. W. Hill and N. G. A. Miller, in Methods in membrane biology, 1974, Springer US, pp. 1-68.

35 W. Hübner and A. Blume, Chem. Phys. Lipids, 1998, 96, 99.

36 S. Diaz, F. Amalfa, B. de Lopez and E. A. Disalvo, Langmuir, 1999, 15, 5179.

37 H. D. Andersen, C. Wang, L. Arleth, G. H. Peters and P. Westh, Proc. Natl. Acad. Sci. U. S. A., 2011, 108, 1874.

38 G. Moiset, C. A. López, R. Bartelds, L. Syga, E. Rijpkema, A. Cukkemane and S. J. Marrink, J. Am. Chem. Soc., 2014, 136, 16167.

39 H. L. Casal and H. H. Mantsch, Biochim. Biophys. Acta, Biomembr., 1984, 779, 381. 